\title{
Research of Industrial Aggregation and Its Regional Economic Growth
}

\author{
Yuran Gao ${ }^{1}$ \\ ${ }^{1}$ No. 1 Jalan Taylor's 47500 Subang Jaya, Selangor Darul Ehsan Malaysia.
}

Keywords: industrial aggregation; regional economic growth; social development

\begin{abstract}
Since the reform and opening-up, in order to make up for the lack of commodity circulation under the planned economic system, the professional market has developed rapidly under the government's support. The existence of a professional market may indicate the existence of certain industrial clusters and can promote the aggregation and development of industries. The role of the professional market in the development of clusters is reflected in the fact that professional markets can make information more professional and can increase demand to open up markets. The existence of collective efficiency in industrial clusters is of great significance to the development of regional economies.
\end{abstract}

\section{Introduction}

Since the reform and opening up, China's eastern coast has maintained a relatively high level of economic growth through the institutional advantages of reform and opening up and the support of regional developmental tilt policies. The economic growth rate in the eastern coastal areas has not only far surpassed that of the central and western regions, but has also become increasingly prominent in China's economy as a whole. At the same time, professional markets and local industrial clusters have risen in the developed coastal regions of southeast China. It is generally believed that there is a clear mutual promotion relationship between professional markets and industrial clusters: professional markets usually serve as the center of price formation for industrial clusters and have strong industrial attraction; and industrial clusters can provide a large number of commodities for professional markets, which is beneficial to commodities. The formation of competitive prices has contributed to the continued prosperity of the professional market. The professional market in Guangdong rose in the 1980s, because the professional market not only met the consumption level of the residents at that time, but also solved the problem of difficult sales of township and township enterprises. It also drove up the upstream and downstream supply and marketing channels, and promoted the circulation of goods. With the development of related industries, professional markets have grown by leaps and bounds. The rise of the professional market has led to the emergence of local industrial clusters. Typical examples include clothing in Dongguan, lighting in Guzhen Township in Zhongshan, and building pottery in Nanzhuang, Foshan. The distinctive professional towns not only have an active role in Guangdong's economy. In the late 1990s, some emerging modern professional markets emerged in Guangdong. The rise and fall of the professional market has affected the industrial clustering power of the Guangdong region. Faced with the gradual opening up of the circulation sector, foreign capital has entered in large numbers and the goal of upgrading professional markets is a long way to go. Based on the quantitative analysis of industrial clustering, professional market and economic development, this article takes the specialty town of Guangdong Province as an example to study how to upgrade professional markets, foster industrial clusters, and promote economic growth. This is of great practical significance.

The connotation of industrial agglomeration effect. Industrial agglomeration mainly means that within the scope of a reasonably large area, a number of similar enterprises that produce a certain product are brought together. Accordingly, in order to effectively cooperate with the production and development of these enterprises, they can provide corresponding products and services. Downstream companies and some related service industries are clustered together at high density. The formation of industrial agglomeration effect is due to the strong influence and driving force of 
these same types of enterprises, which effectively promoted the economic development in this area [1]. The significance of industrial agglomeration. The appearance of the industrial agglomeration effect depends on the accumulation of the same types of enterprises. These enterprises have a competitive and cooperative relationship in the production and operation process, and can not only effectively divide the division of work between the enterprise and the industry, but also It can also effectively control the cost of production and construction, and promote the local regional economy to achieve good development results [2]. Under the influence of the industrial agglomeration effect, the relationship between different companies and industries can be promoted to become more harmonious, mainly because this effect can effectively solve the contradiction between division of labor specialization and transaction convenience, gradually forming a variety of high efficiency Production organization. Under this kind of development situation, the competitiveness of the enterprises within the industrial agglomeration area is constantly improving and can gradually become a good representative of the local economy with competitiveness [3]. In the actual development process, the industrial agglomeration effect can also effectively provide more labor employment opportunities, not only boosting the local people's economic income, but also attracting people from other backward areas, which is positive for the effective promotion of urban modernization construction. The role and significance [4]. The formation of industrial agglomeration effects not only needs to rely on the good operating and development effects of local enterprises of the same type, but also depends on the local social culture, geographical environment, and initial development. In the process of gradual formation of industrial agglomeration effects, it has been affected by many factors: First, transportation factors and transportation are one of the important preconditions for industrial agglomeration. Transit stations and hubs for transportation will give local enterprises full development. Provide good conditions for the production, transportation and circulation of enterprises to provide greater help [5]. Second, the role of government support. The government's policy support, capital, and technical support will effectively promote the formation of industrial agglomeration. Especially in the early stages of the development of some enterprises, the good support of the local government will lay an important foundation for the operation and development of the company and will attract more resources and labor. At the same time, the government can play a good guiding role in the competition among enterprises. Third, the construction of infrastructure. Infrastructure is an important prerequisite for people's production and living. In areas where industrial agglomeration effects are more obvious, their own infrastructure construction is relatively sound and reasonable.

\section{Measurement of Regional Industrial Aggregation Degree}

To conduct comprehensive and detailed analysis and research on the actual conditions of industrial agglomeration, a comprehensive assessment of the extent of its agglomeration is required. This forms a corresponding measure, mainly focusing on the following aspects: first, the entropy index; secondly, Industry concentration; third, the Hare-Keay index; fourth, the Hirschman-Hervey index; fifth, the spatial Gini coefficient; sixth, the spatial concentration index. Among these indicators, the main tool that can be used in the process of comprehensive measurement of industrial agglomeration is the location entropy method. This method is very simple to use during actual use and can easily obtain multiple data. Can fully reflect on the characteristics of the local industry. Location entropy, also known as regional specialization index, can comprehensively measure the relative advantages of an industry in the regional production structure compared to the national level.

The comprehensive and healthy development of the industrial agglomeration effect will play a positive role in promoting the sustained growth of the regional economy. Effective analysis and research on this situation, and actively designing a model of industrial agglomeration and economic growth can play a good role. effect. For industrial clustering and economic growth analysis and research, can use different indicators of industrial agglomeration. This article mainly selects the per capita GDP of a province in China as an important indicator of economic growth. At the same time, the number of enterprises in the chemical fiber manufacturing industry in the province, the net fixed 
assets, the number of laborers employed, the total industrial output value, and taxes are selected. The former profit and the ratio of the country, and so on, indicate the impact of industrial agglomeration on regional economic growth.

Specific empirical analysis. This article wants to conduct a comprehensive study and demonstration on the positive impact of the industrial agglomeration effect of a province on regional economic growth. First, it needs to comprehensively collect the data needed for the empirical model. After the data is effectively processed, the following table can be obtained. Based on the above data, a comprehensive analysis of the province's per capita economic aggregates and industry agglomeration indicators was conducted, mainly using the Eviews3.1 regression, and the corresponding relationship model can be derived as follows:

$$
\begin{gathered}
\text { RGDP=- } 21 \text { 700.0116+923.8715379*AQY+87 } \\
\text { 521.74461*AZG-t(-0.65)(0.07)(10.64)52306.30956*AGD+117 751.5946*AGZ- } 6 \\
\text { 071.772877*ASQ(-2.13)(8.50)(-0.98) }
\end{gathered}
$$

From the above model, when the average number of workers increases by 1 unit, the per capita GDP of the province will increase by about 88942 units, which means that the more workers there are, the more obvious the economic growth, and the average industrial With the increase of the total output value, the per capita gross domestic product in the province is also increasing, which effectively demonstrates that industrial agglomeration has a positive effect on the growth of the regional economy. Judging from the economic development of the province, strengthening the good development of industrial agglomeration will effectively improve regional economic development in a large extent.

First, policies and policies have always been the main conditions and motivations for changes in the accumulation of technological factors. Agglomeration is bound to be influenced by policies. Domestic governments have different strategies for the development of different regions. Different policies will be implemented with the help of certain policy orientations. Local governments will formulate corresponding policies based on the actual economic development of the region under central unified management, central and local governments. More pro-prone tax or fiscal policies will have different effects on the concentration of technological factors. The economic elements are profit-driven, where they can continue to flow when their interests are satisfied, and then they can interact with other elements in these areas, and then cause agglomeration between different elements. At present, the eastern part of the country is generally guided by the policy of the central government. This orientation is the fundamental reason why the concentration of technical elements in the eastern region is higher than in the central and western regions. Second, institutional variables. Domestically, when formulating the economic system, it is considered from the overall perspective of the entire country. It has integrity and unity, but these policies are only the general direction, and there will still be great regional differences in different places because domestic Most of the policies, laws, and various systems are from the national and macro perspectives. Therefore, the requirements for unity are usually made. However, the differences in each area require specific analysis of specific issues. Differences in resources and customs, etc., will establish economic systems according to their own conditions. Moreover, institutional development and change have path dependence. A certain institution will usually change based on the initial choice, but it is difficult to abandon all the original choices. The influence of institutional factors is not worse than that of policies, and relatively speaking, it is relatively open. Sex and a more friendly institutional environment are more attractive to technological elements. Third, industrial agglomeration. According to the theory of industrial agglomeration, after the formation of certain industrial clusters, the speed of agglomeration between other elements will be accelerated in certain regions, so the technical factors are also affected by industrial agglomeration. The higher the level of industrial agglomeration in a certain area, the more attractive it is to the corresponding technical elements and the higher the degree of concentration of technological elements. Domestic northern and southern areas such as Guangzhou, Shenzhen and Shenzhen, because of the high concentration of knowledge-intensive industries, and the corresponding degree of technological agglomeration are 
also very high, and thus form a benign cycle, and the degree of concentration of technical elements is also increasing.

\section{Conclusion}

In carrying out economic construction work and promoting economic growth, it is necessary to actively exert the advantages and effects of industrial agglomeration. To actively play the role of industrial agglomeration in promoting regional economic growth, we can actively play a regulatory role for the government. The formation of industrial agglomeration effects not only requires the development of the market itself, but also requires the government's own good regulation and guidance. At the same time, it is also necessary to actively and effectively improve the local investment environment, actively attract foreign investment, and continuously increase research and development efforts in technological innovation. Capital and science and technology are still a good support and an important foundation for economic development. Applying both to the industrial agglomeration effect, we can effectively enhance the vitality and competitiveness of the regional economy.

\section{References}

[1] Huang Hui, Jin Fengjun. The influence of technological factors agglomeration on the regional economic growth difference in China[J]. Economic Geography, 201, (8):341-344.

[2] Mi Juan, Zhang Chuyi. Analysis of the Impact of Factor Clustering on Regional Economic Growth[J]. Research in Business Economy, 2012, (19): 124-125.

[3] Wang Guixin, Zhang Yu, et al. Total factor productivity, industrial agglomeration and economic growth since China's reform[J]. Social Sciences, 2012, (11):39-49.

[4] Zhao Weiliang, Jing Tao. Agglomeration of factors and development of regional economy_-Taking Dalian as an example[J]. Journal of Liaoning Normal University: Social Sciences, 2016, (5):42-47.

[5] Martin, Ottaviano. Growth and Agglomeration [J]. International Economic Review, 2001, 42, (4): 947-968. 